\title{
Hydrogen steelmaking. Part 1: Physical chemistry and process metallurgy
}

\author{
Fabrice Patisson ${ }^{1, *}$, Olivier Mirgaux ${ }^{1}$, and Jean-Pierre Birat ${ }^{2}$ \\ ${ }^{1}$ Université de Lorraine, IJL, Labex DAMAS, Nancy, France \\ ${ }^{2}$ IF Steelman, Metz, France
}

Received: 27 October 2021 / Accepted: 14 December 2021

\begin{abstract}
Pushed to the forefront by the objective to drastically reduce the $\mathrm{CO}_{2}$ emissions from the steel industry, a new steelmaking route based on hydrogen and electricity is the subject of a great deal of attention and numerous $\mathrm{R} \& \mathrm{D}$ projects. The first step is to chemically reduce iron ore with $\mathrm{H}_{2}$, which is produced by electrolysis of water with low-carbon electricity, and then to transform the direct reduced iron into steel in an electric arc furnace. The second step is a conventional one, similar to that used for scrap recycling. The first step is similar to the so-called direct reduction process but would use pure electrolytic $\mathrm{H}_{2}$ instead of the $\mathrm{H}_{2}-\mathrm{CO}$ syngas obtained from natural gas reforming. In this paper, we first show how the reduction by pure $\mathrm{H}_{2}$ takes place at the microscopic level of the iron oxide grains and pellets. The three-step (hematite-magnetite-wüstite-iron) reduction occurs successively in time and simultaneously in the pellets. Secondly, a sophisticated kinetic model of the reduction of a single pellet based on the experimental findings is described. Lastly, we present a mathematical model for the simulation of the reduction by pure $\mathrm{H}_{2}$ in a shaft furnace, which can be very useful for the design of a future installation. The main results are that using pure hydrogen, the reduction kinetics are faster and can end with full metallization, the direct reduction process would be simpler, and the shaft furnace could be squatter. The gains in terms of $\mathrm{CO}_{2}$ emissions are quantified ( $85 \%$ off) and the whole route is compared to other zero-carbon solutions in Part 2.
\end{abstract}

\section{Introduction}

Given its volume (1.88 billion tons of steel produced in 2019 [1]) and its demand for fossil energy, mainly coal, the steel industry is one of the world's leading emitters of $\mathrm{CO}_{2}(7 \%$ of global anthropogenic emissions [2]). However, this situation is not new and the steel sector has been investigating low-carbon solutions for producing steel, including hydrogen-based ones, for the last 60 years at least $[3,4]$. Many programs were conducted in the 2000s decade, including several large international ones: the ULCOS (Ultra-low $\mathrm{CO}_{2}$ steelmaking) program in Europe $[5,6]$ and the $\mathrm{CO}_{2}$ Breakthrough program at world scale $[7,8]$ were the most important. The 2010s were a trough period, when the R\&I efforts slowed down significantly, both because of the crisis and of the need for financing institutions to reexamine and refocus their support. More recently, a consensus emerged about the need to act with determination to control climate change: the COP21 Paris

\footnotetext{
ESTEP H2GreenSteel Web-Workshop, Virtual, 7th, 21st, 28th May and 11th June 2021

* e-mail: fabrice.patisson@univ-lorraine.fr
}

agreement and the Green Deal Strategy of the European Commission, soon duplicated in other regions of the world, were the major reasons for a change of speed. This led to an explosion of project proposals, in response to financing opportunities for research and further industrial implementation opening on this topic, especially in the EU (HEU program, Innovation Fund, etc.). Those current projects are extensively described in Part 2 of this 2-paper series [9]. Even reputable newspapers with a very large audience are interested in this evolution [10].

The whole hydrogen route to steel was first defined and evaluated in the ULCOS program (Fig. 1).

The basic idea is to use hydrogen as a reductant for the important step that consists in reducing the iron ore into metallic iron, thus releasing harmless $\mathrm{H}_{2} \mathrm{O}$ instead of $\mathrm{CO}_{2}$, and to use carbon-lean electricity as much as possible. Of course $\mathrm{H}_{2}$ cannot be produced from natural gas as usual. Water electrolysis using carbon-lean electricity was selected as the best process to get the huge amount of "green" hydrogen needed $\left(70000 \mathrm{~m}^{3} \mathrm{STP} / \mathrm{h}\right.$ for $1 \mathrm{Mt}_{\text {steel }} /$ year$)$. The DRI (direct reduced iron) is transformed into steel in an electric arc furnace, while the end of the route is identical to that used to produce secondary steel from recycled scrap. 


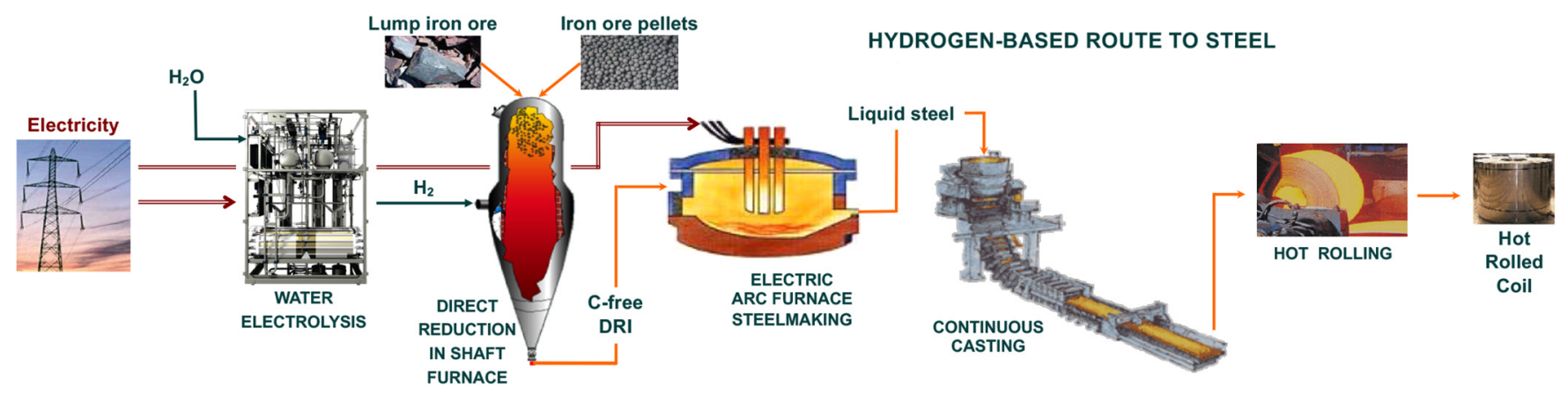

Fig. 1. ULCOS hydrogen-based route to steel [11].

The main challenges of this route are in our opinion (1) to know how to design and operate a shaft furnace under pure hydrogen, (2) to know how to use a carbon-free DRI in the electric arc furnace, and (3) to be able to produce massively and at low cost green hydrogen. Point (3) is clearly crucial and is discussed in Part 2 [9]. Note that the abundance of large electrolyser projects is a precursor. Point (2) probably deserves specific investigations. It should be noted, however, that the current trend to manufacture and use DRI with $4 \%$ carbon is based primarily on economic considerations. The addition of carbon in the electric furnace is a daily practice. Point (1) is the main focus of this paper. We will discuss it from the perspective of laboratory studies and mathematical modeling. The most advanced current projects, such as HYBRIT [12], are already approaching it from the point of view of reduced-scale industrial demonstration.

Of course, this route is clearly different from the conventional BF-BOF (Blast Furnace-Basic Oxygen Furnace) route, and also different from the existing DREAF (Direct Reduction-Electric Arc Furnace) route, which uses a $\mathrm{CO}-\mathrm{H}_{2}$ syngas, produced from natural gas. A comparison of the energy, environmental and economic performance of these routes, based on a cradle-to-gate life cycle approach, was carried out in ULCOS and the main results are presented in Part 2 [9]. A comparison with other estimates in the literature is also given in [11]. The most important result, which justifies the current focus on this breakthrough route, is the estimation of its specific greenhouse gas emissions: between 25 and $300 \mathrm{~kg}_{\mathrm{CO} 2 \mathrm{eq}} / \mathrm{t}$ of steel, depending on the sources, compared to $1850 \mathrm{~kg}$ for the classical route, i.e. more than $85 \%$ off.

The present paper is organized as follows: first, the physical-chemical aspects of the iron oxide reduction by hydrogen are recalled, the features that can influence an industrial process are highlighted, and a comparison with $\mathrm{CO}$ is given; second, the findings obtained from mathematical modeling, both on the pellet and reactor scales, are discussed.

\section{Chemical characteristics of the reduction of iron ore by hydrogen}

Most iron ores are oxides, most often hematite $\mathrm{Fe}_{2} \mathrm{O}_{3}$, and the reduction of this oxide to metallic iron by $\mathrm{CO}$, by $\mathrm{H}_{2}$ or by $\mathrm{CO}-\mathrm{H}_{2}$ mixtures have been extensively studied. More than 20000 articles were devoted to it since 1900 [11]. This reflects the economic importance of this reduction, which is the first and central step in the production of steel. Without attempting to examine all of this work here, we will recall here the relevant features.

The reduction of hematite to iron, whether by $\mathrm{CO}$ or by $\mathrm{H}_{2}$, takes place in two or three stages, depending on whether the temperature is above or below $570^{\circ} \mathrm{C}$. Hematite $\mathrm{Fe}_{2} \mathrm{O}_{3}$ is first reduced to magnetite $\mathrm{Fe}_{3} \mathrm{O}_{4}$, then to wüstite $\mathrm{Fe}_{\mathrm{y}} \mathrm{O}$, a non-stoichiometric compound, and finally to iron.

$$
\begin{gathered}
3 \mathrm{Fe}_{2} \mathrm{O}_{3}+\mathrm{CO}=2 \mathrm{Fe}_{3} \mathrm{O}_{4}+\mathrm{CO}_{2}, \\
\mathrm{Fe}_{3} \mathrm{O}_{4}+\frac{16}{19} \mathrm{CO}=\frac{60}{19} \mathrm{Fe}_{0.95} \mathrm{O}+\frac{16}{19} \mathrm{CO}_{2}, \\
\mathrm{Fe}_{0.95} \mathrm{O}+\mathrm{CO}=0.95 \mathrm{Fe}+\mathrm{CO}_{2}, \\
3 \mathrm{Fe}_{2} \mathrm{O}_{3}+\mathrm{H}_{2}=2 \mathrm{Fe}_{3} \mathrm{O}_{4}+\mathrm{H}_{2} \mathrm{O}, \\
\mathrm{Fe}_{3} \mathrm{O}_{4}+\frac{16}{19} \mathrm{H}_{2}=\frac{60}{19} \mathrm{Fe}_{0.95} \mathrm{O}+\frac{16}{19} \mathrm{H}_{2} \mathrm{O}, \\
\mathrm{Fe}_{0.95} \mathrm{O}+\mathrm{H}_{2}=0.95 \mathrm{Fe}+\mathrm{H}_{2} \mathrm{O} .
\end{gathered}
$$

The so-called Chaudron or Baur-Glaessner diagram (Fig. 2) shows the stability ranges of the different phases as a function of temperature and oxidizing power of the gas. An important deduction is that, with $\mathrm{CO}$, the reduction is thermodynamically easier at low temperature than at high temperature, the opposite being true with $\mathrm{H}_{2}$ (see the arrows at $1000^{\circ} \mathrm{C}$ in the diagram). At $800^{\circ} \mathrm{C}$, it is equivalent. Moreover, thermodynamics indicates us (Tab. 1) that the first reduction is exothermic, and is more so with $\mathrm{CO}$, the second is endothermic, and is less so with $\mathrm{CO}$, while the third is exothermic with $\mathrm{CO}$ whereas it is endothermic with $\mathrm{H}_{2}$. It will thus be necessary overall to provide energy to reduce by $\mathrm{H}_{2}$, in addition to the energy necessary to heat the materials.

The reduction reactions (1-6) are heterogeneous gassolid reactions. They take place at the interfaces between gas and solid and between solids. In addition to chemical processes (adsorption, reaction, desorption), physical transport processes are also involved. Indeed, the gaseous 


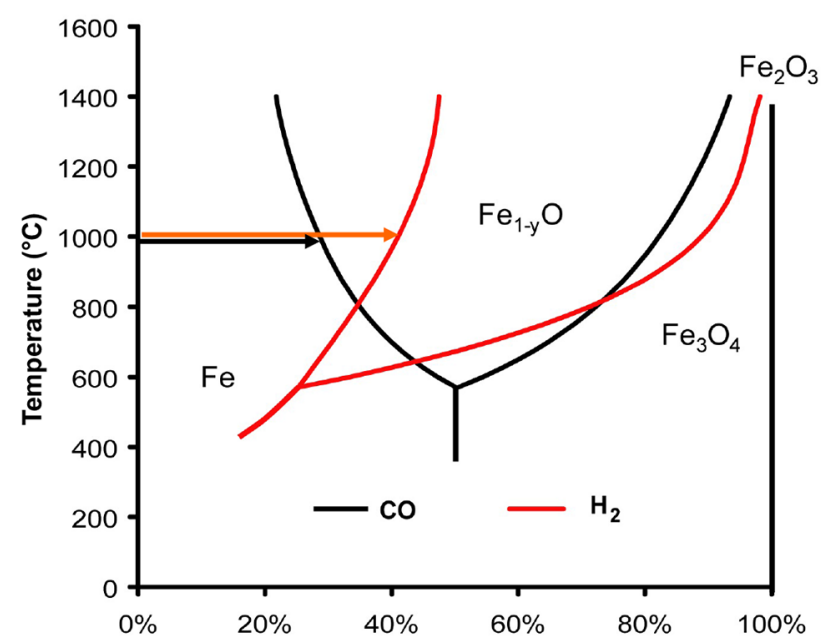

$\mathrm{CO}_{2}$ (resp. $\mathrm{H}_{2} \mathrm{O}$ ) content (vol.\%) in the mixture CO-CO $\left(\right.$ resp. $\mathrm{H}_{2}-\mathrm{H}_{2} \mathrm{O}$ )

Fig. 2. Phase diagram of the iron phase domains as a function of the oxidizing power of the gas and temperature, for the gas mixtures $\mathrm{CO}-\mathrm{CO}_{2}$ and $\mathrm{H}_{2}-\mathrm{H}_{2} \mathrm{O}$. The arrows represent the driving force for the wüstite-to-iron reduction.

Table 1. Heat values of the reduction reactions.

\begin{tabular}{lc}
\hline Reaction & $\Delta_{\mathrm{r}} \mathrm{H}_{800}{ }^{\circ} \mathrm{C}\left(\mathrm{J} \mathrm{mol}^{-1}\right)$ \\
\hline $3 \mathrm{Fe}_{2} \mathrm{O}_{3}+\mathrm{CO}=2 \mathrm{Fe}_{3} \mathrm{O}_{4}+\mathrm{CO}_{2}$ & -40040 \\
$3 \mathrm{Fe}_{2} \mathrm{O}_{3}+\mathrm{H}_{2}=2 \mathrm{Fe}_{3} \mathrm{O}_{4}+\mathrm{H}_{2} \mathrm{O}$ & -6020 \\
$\mathrm{Fe}_{3} \mathrm{O}_{4}+\mathrm{CO}=3 \mathrm{FeO}+\mathrm{CO}_{2}$ & 18000 \\
$\mathrm{Fe}_{3} \mathrm{O}_{4}+\mathrm{H}=3 \mathrm{FeO}+\mathrm{H}_{2} \mathrm{O}$ & 46640 \\
& \\
$\mathrm{FeO}+\mathrm{CO}=\mathrm{Fe}+\mathrm{CO}_{2}$ & -17610 \\
$\mathrm{FeO}+\mathrm{H}_{2}=\mathrm{Fe}+\mathrm{H}_{2} \mathrm{O}$ & 16410 \\
\end{tabular}

reactant must reach the reaction site and the gaseous product must be evacuated, generally by gas phase diffusion. Diffusion of species in the solid phase can also occur. This implies that the situation will be completely different if one reduces dense grains of a pure oxide, a small bed of powder of the same oxide, a lump of ore or even a pellet (Fig. 3). The size of the grains, lumps or pellets, the total porosity and the distribution of the pore sizes

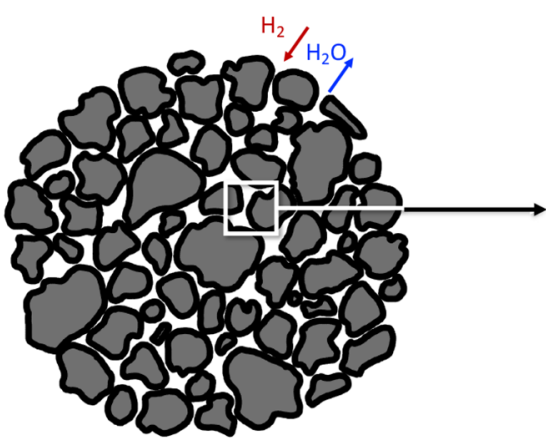

(a)

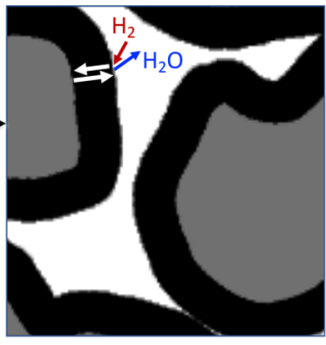

(b)
Fig. 3. Schematic representation of a pellet (a) and pores around constituting grains (b) showing the transport processes associated with the chemical reaction.

influence the course of the reduction and thus its overall rate, even for identical conditions of temperature and composition of the reducing gas. This explains the great variety of behaviors, sometimes seeming contradictory, reported in the literature. It is possible to obtain intrinsic kinetic parameters but, in order to be applicable to real systems, they must be associated with measurements of physical and geometrical parameters and with a modeling of the transport processes.

In the case of the reduction of ore pellets, such as industrial pellets, which are initially composed of small hematite grains, we have shown [13] that the porous and granular structure evolves with the reduction (Fig. 4). Initially, a slight porosity appears on the surface of the grains when hematite is transformed into magnetite. From magnetite to wüstite and then to iron, the same evolution by increase in the microporosity continues if the reduction is conducted at low temperature (less than $800^{\circ} \mathrm{C}$ ). But at higher temperatures, the wüstite grains disintegrate and the iron phase that forms around the wüstite grains is dense (Fig. 4h). The iron spreads around the small wüstite grains, which we called crystallites, and tends to join these crystallites together. The size of the grains and pores increases with the temperature and with the course of reaction. Figure 5 shows an example of the increase in porosity and mean pore size for a CVRD-DR (from Vale, Brazil, Direct Reduction grade) pellet, before and after reduction by $\mathrm{H}_{2}$ at $1000{ }^{\circ} \mathrm{C}$. All these changes have of course consequences on the reaction kinetics.

The influence of temperature on the reduction kinetics with $\mathrm{H}_{2}$ is complex as shown in Figure 6 .

From 600 to $900{ }^{\circ} \mathrm{C}$, and from 1100 to $1200^{\circ} \mathrm{C}$, the temperature accelerates the kinetics as expected. Between 900 and $1100^{\circ} \mathrm{C}$, however, we observe that the kinetics slow down after about $70 \%$ conversion. We also note a final slowdown for the temperature of $700{ }^{\circ} \mathrm{C}$. These observations reflect the fact that several potentially-limiting kinetic processes are at work during the wüstite-to-iron conversion. According to [13], the kinetics take place in a mixed regime (controlled by both chemical reaction and intergranular diffusion) but at high temperature a 


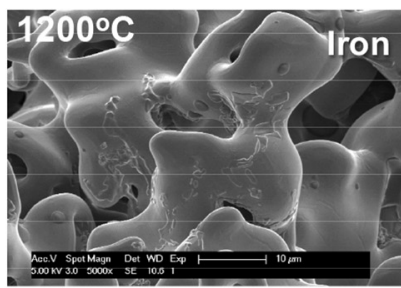

(g)

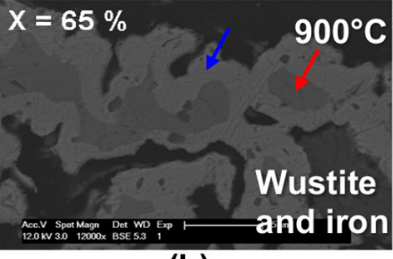

(h)

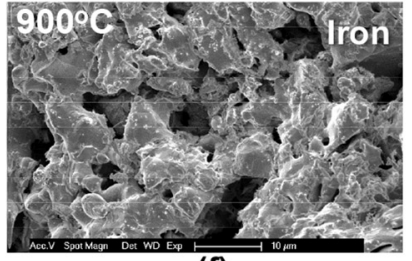

(f)

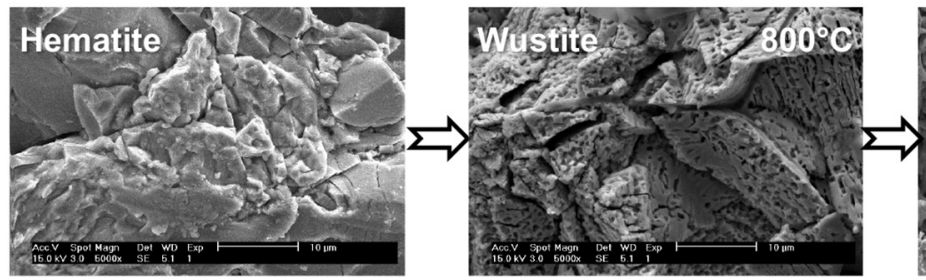

(a) (b)

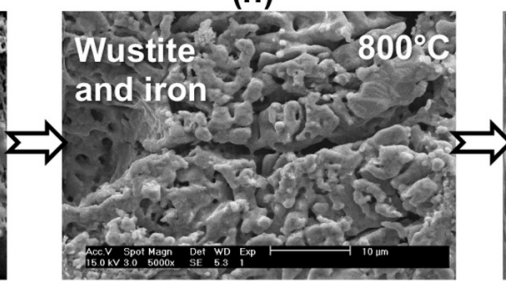

(c)

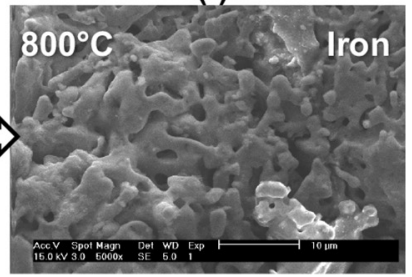

(d)

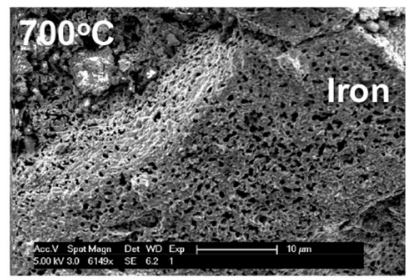

(e)

Fig. 4. SEM (Scanning Electron Microscope) micrographs showing the morphological changes at the granular scale in CVRD-DR pellets; (a) to (d): grains in different stages of a reduction at $800^{\circ} \mathrm{C}$; (d) to (g): iron grains after reduction at different temperatures; (h): polished cross-section at a conversion degree of $65 \%$ of a sample reduced at $900{ }^{\circ} \mathrm{C}$, the red arrow points to shrinking wüstite cores (dark gray) surrounded with a spreading layer of iron (light gray), indicated by the blue arrow. All images by SE (secondary electrons), except (h) BSE (backscattered electrons). Reducing gas used: $2 \mathrm{~L} / \mathrm{min}_{2}-\mathrm{He}(60-40$ vol.\%) in a thermobalance.

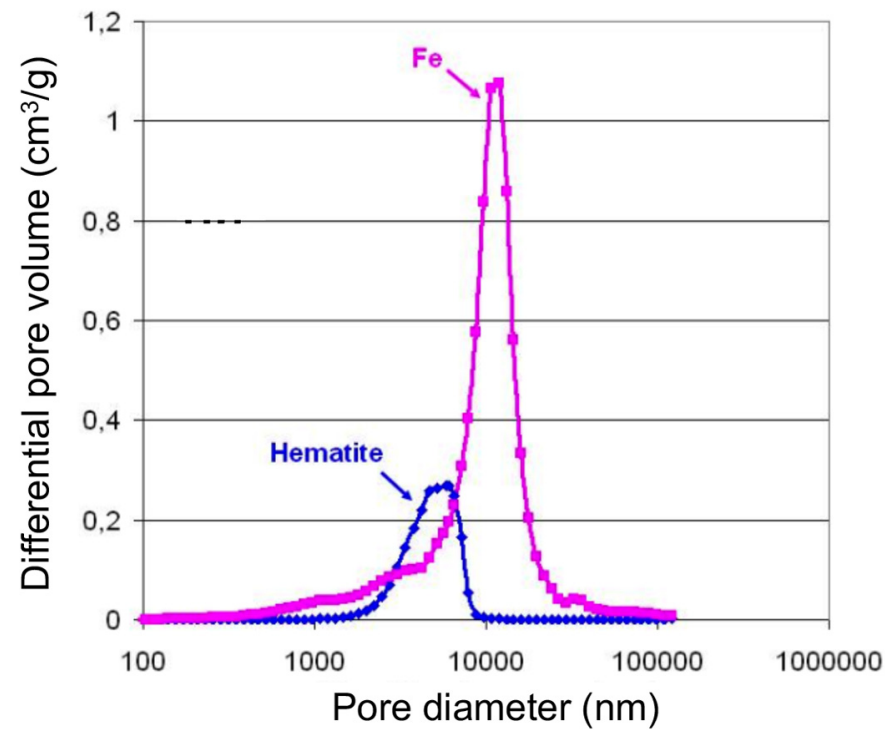

Fig. 5. Pore size distribution of a CVRD-DR pellet before and after reduction by $\mathrm{H}_{2}$ at $1000^{\circ} \mathrm{C}$.

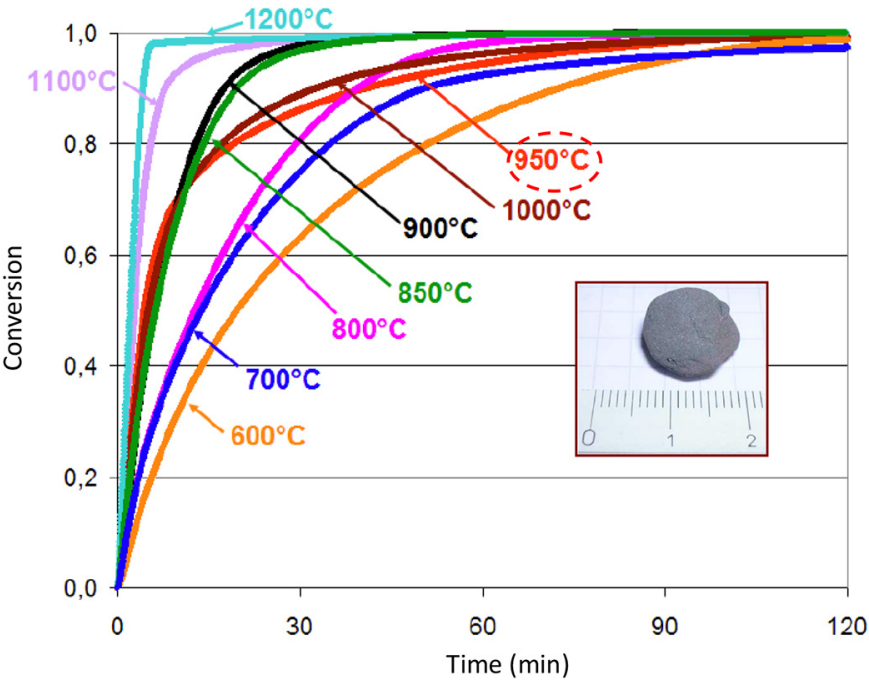

Fig. 6. Effect of temperature on the kinetics of reduction of one CVRD pellet under $\mathrm{H}_{2}\left(40 \% \mathrm{H}_{2}\right.$ in $\left.\mathrm{He}\right)$, measured by thermogravimetry. 


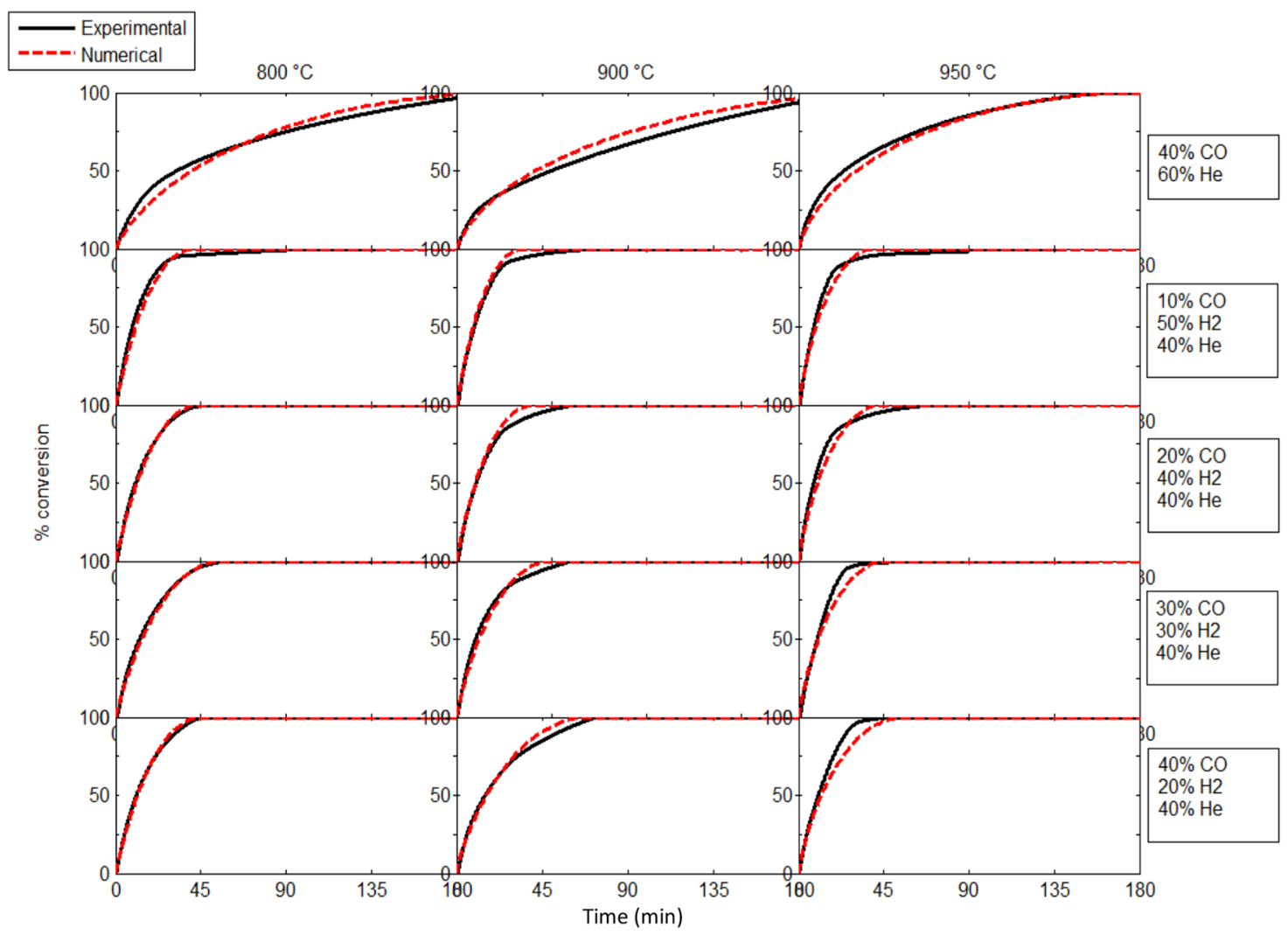

Fig. 7. Reduction of CVRD pellets under $\mathrm{CO}-\mathrm{H}_{2}$ mixtures in a thermobalance [18].

transport step by solid phase diffusion through the dense iron layer is also involved. The latter is more difficult through the Fe- $\gamma$ austenite (formed above $912^{\circ} \mathrm{C}$ ) than through the $\mathrm{Fe}-\alpha$ ferrite, which explains the final kinetic slowdown at 950 and $1000^{\circ} \mathrm{C}$. These particular behaviors can of course have repercussions on the performance of industrial shaft furnaces and in particular on the final degree of metallization obtained.

Finally, when they compare the reduction kinetics by $\mathrm{CO}$ and $\mathrm{H}_{2}$, the vast majority of authors find that the reduction kinetics by $\mathrm{H}_{2}$ is faster than that by $\mathrm{CO}$, e.g. [13-15]. In the case of $\mathrm{CO}-\mathrm{H}_{2}$ mixtures, such as the reducing gas used for the direct reduction furnaces of MIDREX [16] and HYLENERGIRON [17] processes, the mixture gives results closer to those with pure $\mathrm{H}_{2}$ than those with pure $\mathrm{CO}$. Figure 7 illustrates these results.

\section{Kinetic model of a single pellet}

The modeling of reactors such as shaft furnaces requires a predictive calculation of the rate of the reduction reactions at any temperature and for any gas composition. For this purpose, we have designed a specific model, the kinetic model of a single pellet, which reproduces the observations and results obtained in the laboratory and which can be easily integrated into a multiparticle reactor model. Its principle is based on a geometrical representation of a spherical pellet made up of smaller grains (Fig. 8). Initially the grains are dense hematite. The inter- and intragranular porosity evolves during the reduction. At the wüstite stage, the grains subdivide into crystallites. At the grain scale, the reactions are topochemical, with a shrinking core.

It is thus a more sophisticated model than the shrinking core pellet models, with one or three interfaces, often used in the literature. It should be noted here that experimentally, we do not observe concentric interfaces separating the different oxides and the iron at the pellet scale. The kinetic parameters used are taken from our own experiments (porosity measurements, specific surface) and from model-experiment fitting for the rate constants [19]. From a mathematical point of view, the model remains simple because it is based on the law of additive characteristic times [20]. This law, approximate but validated by several studies, allows us an analytical calculation of the reaction rate, even for mixed regimes. This single pellet model adapted to the reduction of iron ore by $\mathrm{H}_{2}$ and/or $\mathrm{CO}$ is described in more detail in $[13,18,19,21]$.

\section{Multiparticle model of the shaft furnace}

The shaft furnace for the reduction of iron ore with pure $\mathrm{H}_{2}$ is the core of the new process. In a conventional shaft furnace, the iron ore, in the form of pellets or lump ore, slowly descends by gravity into a vertical cylindrical shaft and is reduced by a $\mathrm{CO}-\mathrm{H}_{2}$ mixture flowing upwards countercurrently. This bustle gas is introduced through the sidewall at mid-height and goes out at the top. In the MIDREX process (Fig. 9), the top gas is recycled to feed the burners and the reformer, in combination with natural 

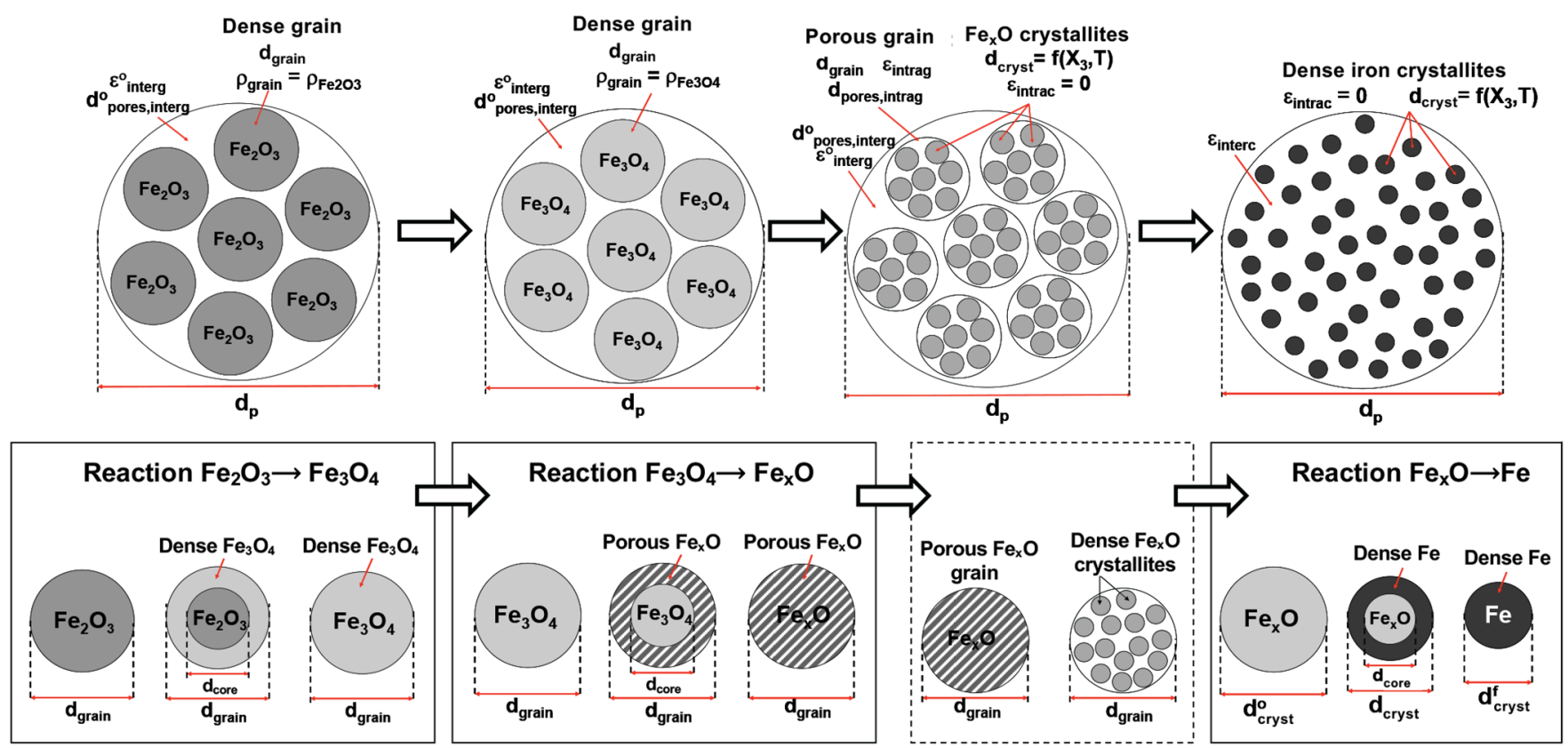

Fig. 8. Representation of the pellet (top row) and grain (bottom row) evolution in the single pellet kinetic model [11].

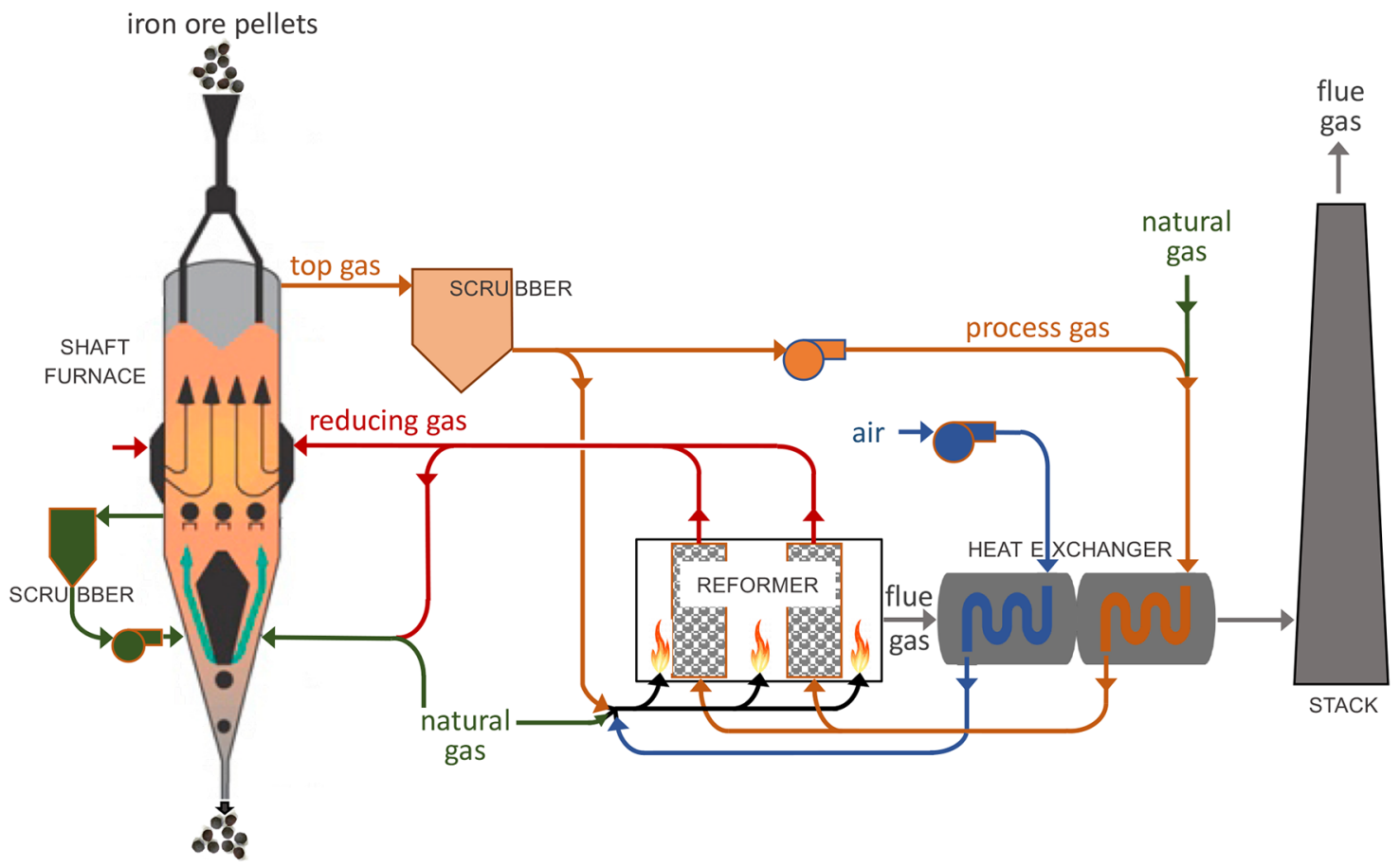

direct reduced iron

Fig. 9. Schematic diagram of the direct reduction process [21].

gas. In the HYL process, the gas loop is somewhat different, the reformer may not exist. The bottom part of the shaft furnace is a cone, in which the DRI is cooled by a looping counterflow of natural gas.

To predict whether a similar shaft furnace could be operated under pure hydrogen, a powerful and economical means of evaluation is mathematical modeling. Several models of DR shaft furnaces have been published, which differ according to the description of the reactor $(1 \mathrm{D}$ or $2 \mathrm{D}$, with or without intermediate and cooling zones), the chemical reactions taken into account and the associated kinetic models, the description of the gas and solid flows, the numerical method of resolution. The most detailed models [21-24] give access to very interesting characteristics of the internal behavior of shaft furnaces. With the exception of REDUCTOR, presented below, none of them has been used so far to predict the operation of a shaft furnace under pure $\mathrm{H}_{2}$. 


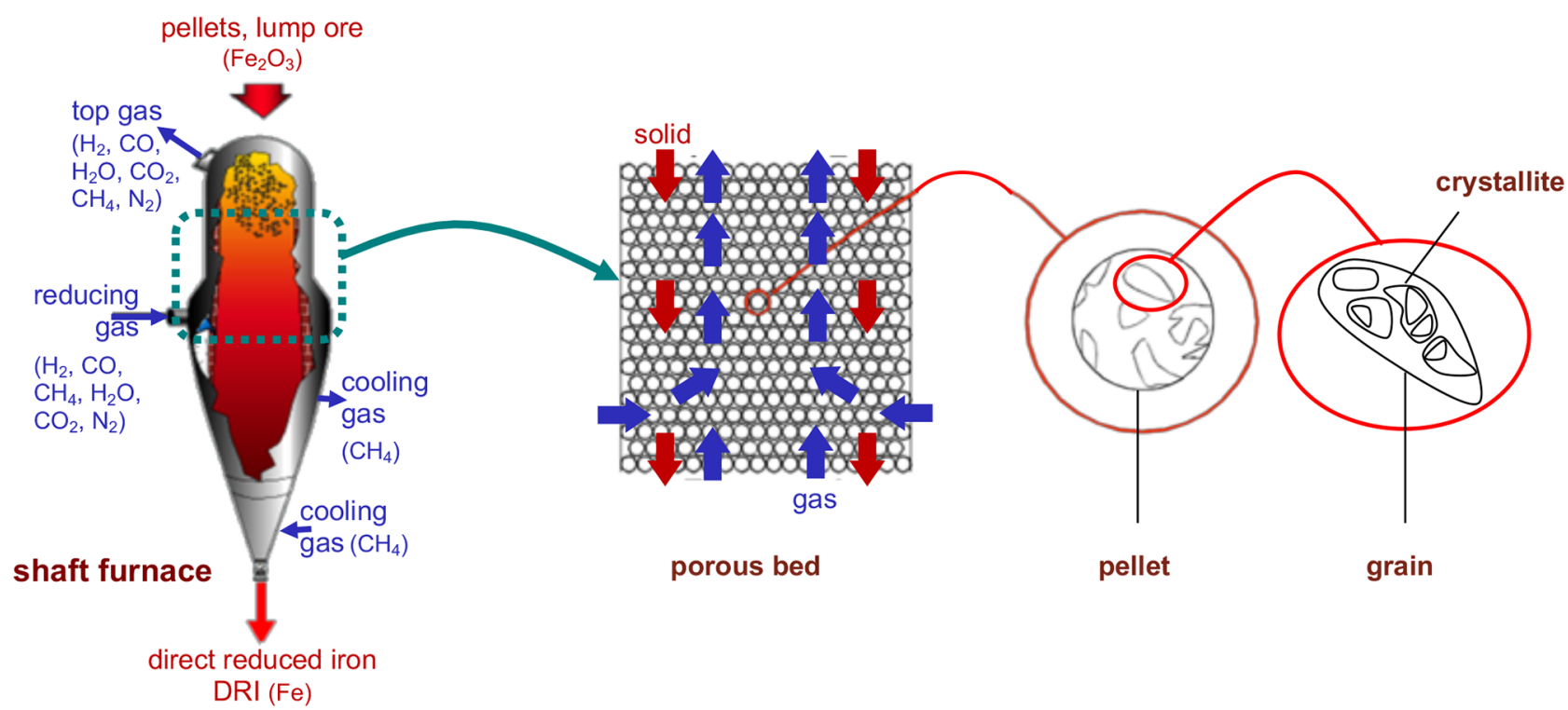

Fig. 10. The four scales in the REDUCTOR model [21].
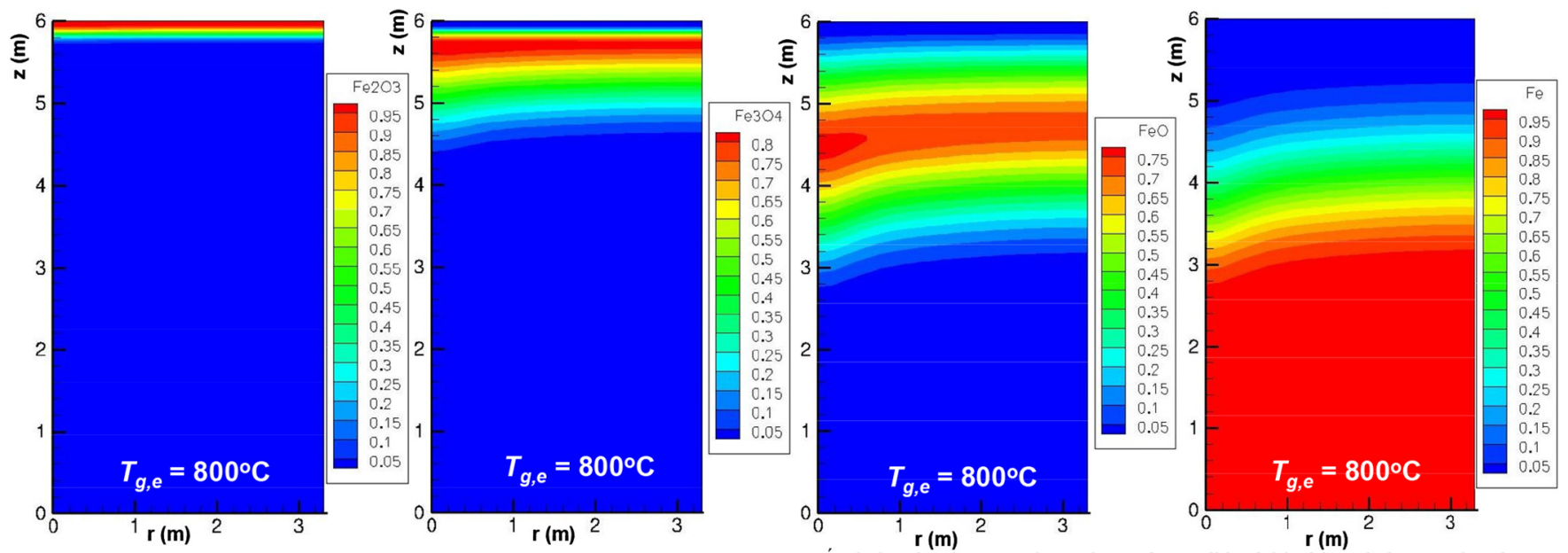

Fig. 11. Calculated solid mass fractions in a shaft furnace fed with $\mathrm{H}_{2}$ at $800{ }^{\circ} \mathrm{C}$. The symmetry axis is on the left-hand side of each map, and the wall is on the right-hand side. The main gas inlet is at the wall near the bottom of the reactor.

The REDUCTOR model simulates the operation of a MIDREX or HYL-ENERGIRON shaft furnace. A cylindrical upper part, a conical lower part and an intermediate cylindrical part are considered. The input data for the calculation are the flow rates, compositions and temperatures of the incoming streams (solid at the top, reducing gas at the side, and cooling gas at the bottom). The same output quantities (DRI at the bottom and gas at the top) are results of the calculation. Four scales are considered: reactor, porous moving bed, pellets and grains (Fig. 10). The main equations solved are material balances on solid species $\left(\mathrm{Fe}_{2} \mathrm{O}_{3}, \mathrm{Fe}_{3} \mathrm{O}_{4}, \mathrm{FeO}, \mathrm{Fe}, \mathrm{C}\right.$, gangue $)$, gaseous species $\left(\mathrm{H}_{2}, \mathrm{CO}, \mathrm{H}_{2} \mathrm{O}, \mathrm{CO}_{2}, \mathrm{CH}_{4}, \mathrm{~N}_{2}\right)$, heat balances on gas and solid, momentum balances. The kinetic model of a single pellet is included as a subroutine of the reactor code.

The equations and the numerical method have already been presented $[11,13,21]$ and will not be repeated here. Two MIDREX direct reduction furnaces of different sizes were simulated by REDUCTOR and the comparison of the calculated results with measurements was used to validate the model $[18,21]$.

Below we present the results of the simulation of a furnace that would operate under pure $\mathrm{H}_{2}$, without $\mathrm{CO}$ and $\mathrm{CH}_{4}$, limited to the reduction zone. The height is $6 \mathrm{~m}$, the diameter $6.6 \mathrm{~m}$. The solid charge consists of hematite pellets, its flow rate is $52 \mathrm{~kg} \mathrm{~s}^{-1}$. The gas $\left(98 \% \mathrm{H}_{2}, 2 \% \mathrm{H}_{2} \mathrm{O}\right)$ enters at $800^{\circ} \mathrm{C}$ with a flow rate of $3634 \mathrm{~mol} \mathrm{~s}^{-1}$ from the side and $100 \mathrm{~mol} \mathrm{~s}^{-1}$ from the bottom.

The map of the mass fractions of the solids (Fig. 11) reveals that the reduction of hematite to magnetite is very fast, followed by the reduction of magnetite to wüstite, then the reduction of wüstite to iron is the slowest. It is however entirely completed at $3 \mathrm{~m}$ below the solid inlet, whereas the whole height is necessary for a metallization of about $95 \%$ in a conventional MIDREX furnace operating under $\mathrm{CO}-\mathrm{H}_{2}$. 


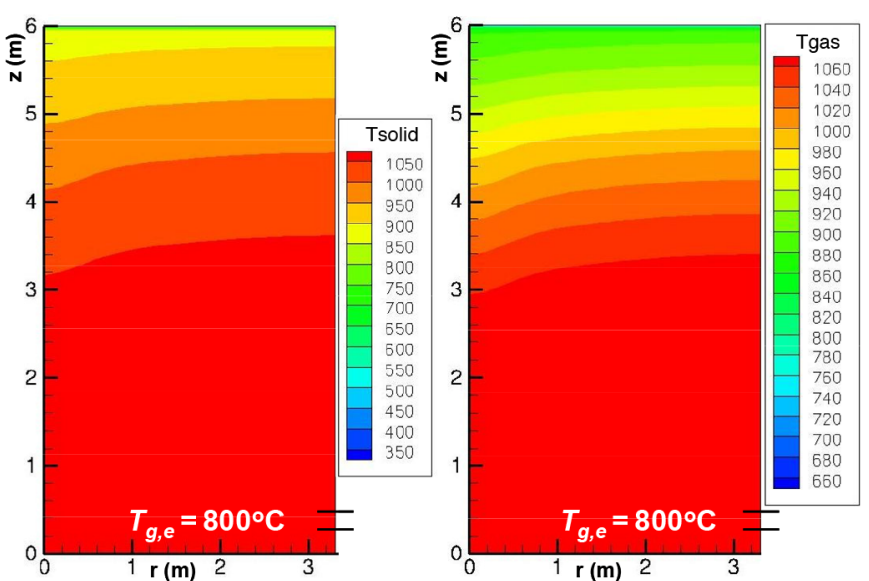

Fig. 12. Calculated temperatures $(K)$ in a shaft furnace fed with $\mathrm{H}_{2}$ at $800^{\circ} \mathrm{C}$.

The temperature map (Fig. 12) shows that gas and solids are almost at the same temperature everywhere, except at the very top where the solid goes very quickly from 25 to $600{ }^{\circ} \mathrm{C}$. Slight radial and especially axial thermal gradients are noted in the upper half of the furnace due to the endothermicity of the reduction. The map of $\mathrm{H}_{2}$ and $\mathrm{H}_{2} \mathrm{O}$ molar fractions (Fig. 13) illustrates the progressive consumption of $\mathrm{H}_{2}$ and the corresponding production of $\mathrm{H}_{2} \mathrm{O}$ (from $\mathrm{z}=3 \mathrm{~m}$ to $\mathrm{z}=6 \mathrm{~m}$ ) corresponding to the reduction of oxides to iron. Not all $\mathrm{H}_{2}$ is used, far from it, since $72 \%$ of $\mathrm{H}_{2}$ remains in the top gas. This is not due to a poor utilization of $\mathrm{H}_{2}$ but to the fact that a flow rate much higher (3.8 times) than the stoichiometric flow rate necessary for the reduction must be circulated in order to heat the furnace.

Figure 14 shows the effect of the reduction gas temperature on the iron mass fraction. The case at $800^{\circ} \mathrm{C}$ has already been presented. At higher temperatures, a complete reduction is obtained faster. Between 900 and $950{ }^{\circ} \mathrm{C}$, the difference is little because of the kinetic slowdown mentioned. Moreover, above $900^{\circ} \mathrm{C}$, the gain seems small compared to the need to spend more energy. At $700{ }^{\circ} \mathrm{C}$, the temperature is not sufficient to heat the furnace and iron appears only very partially, near the injection point.

These simulations need to be complemented by other ones, and confronted with experiments or other recent modeling results $[25,26]$. They do not answer all the questions related to the use of pure $\mathrm{H}_{2}$. However, they clearly show that a complete reduction of iron ore pellets by $\mathrm{H}_{2}$ in a shaft furnace is quite feasible.

\section{Conclusion}

In the context of the fight against global warming, the need to drastically reduce $\mathrm{CO}_{2}$ emissions in the industrial sectors most concerned has recently led the steel industry to seriously consider the hydrogen option. The most promising hydrogen-based steelmaking route is the direct reduction of iron ore by pure $\mathrm{H}_{2}$ followed by electric steelmaking. It indeed combines a certain technological

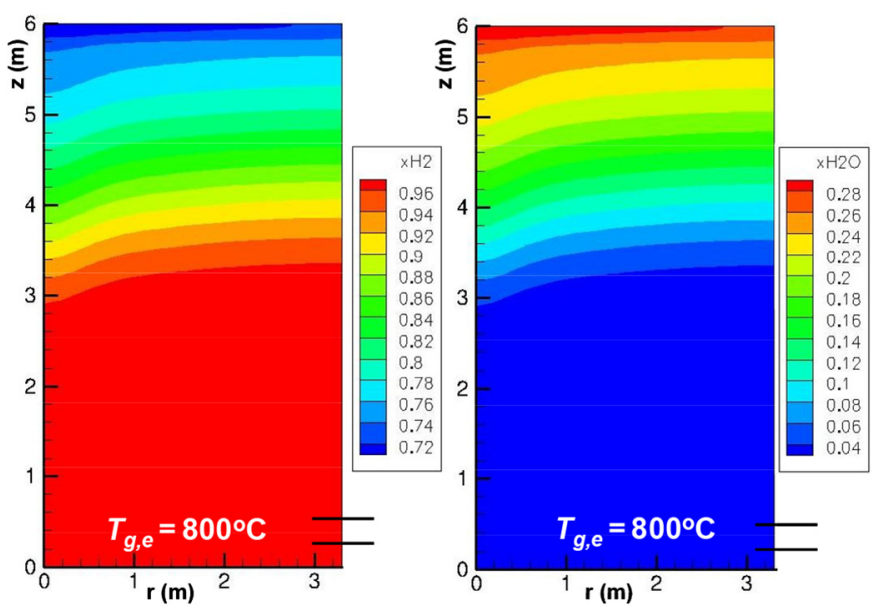

Fig. 13. Calculated molar gas fractions in a shaft furnace fed with $\mathrm{H}_{2}$ at $800^{\circ} \mathrm{C}$.

maturity and very good performance in terms of emissions reduction (more than $85 \%$ decrease). Hydrogen must be green or produced through low-carbon processes, and the solution that appears to be the most efficient to produce the large quantities needed is the electrolysis of water with decarbonized electricity (renewable or nuclear). Numerous projects in line with this new route are starting, focusing either on the development of large capacity electrolysers or, more rarely until now, on the demonstration of the viability of the direct reduction process with pure $\mathrm{H}_{2}$.

The research carried out on this topic at the Institut Jean Lamour, University of Lorraine, France, initiated during the ULCOS program and continued since, has provided a set of valuable results.

The experimental study of the reduction of ore pellets by $\mathrm{H}_{2}$ shows that the reaction is faster than with $\mathrm{CO}$ and that a complete metallization is obtained in the laboratory, even when a dense iron layer is formed around the wüstite grains. The influence of the temperature is complex, with the appearance of kinetic slowdowns at the end of the reaction at 700 and $950{ }^{\circ} \mathrm{C}$. We have proposed a sophisticated single pellet kinetic model based on experimental observations and capable of simulating mixed kinetic regimes.

Dealing with the reactor scale, the use of the REDUCTOR model to simulate a shaft furnace operated under pure $\mathrm{H}_{2}$ has provided significant first results. It seems possible to obtain a complete metallization under $\mathrm{H}_{2}$ and to use a squatter furnace than the current direct reduction furnaces. Temperatures between 800 and $950^{\circ} \mathrm{C}$ seems adequate. However, these simulations should be extended to the case of a complete furnace, including the lower conical zone. The model can be used to guide towards optimal dimensions and operating conditions.

The points that we believe deserve further investigations are: some very scientific questions on kinetic slowdowns, occurrence of sticking, solid flow, more technological questions such as the design and optimal operating conditions of a $\mathrm{H}_{2}$ shaft furnace and its gas loop, the consequences of using carbon-free DRI in the electric furnace, the materials best suited to $\mathrm{H}_{2}-\mathrm{H}_{2} \mathrm{O}$ atmospheres, 

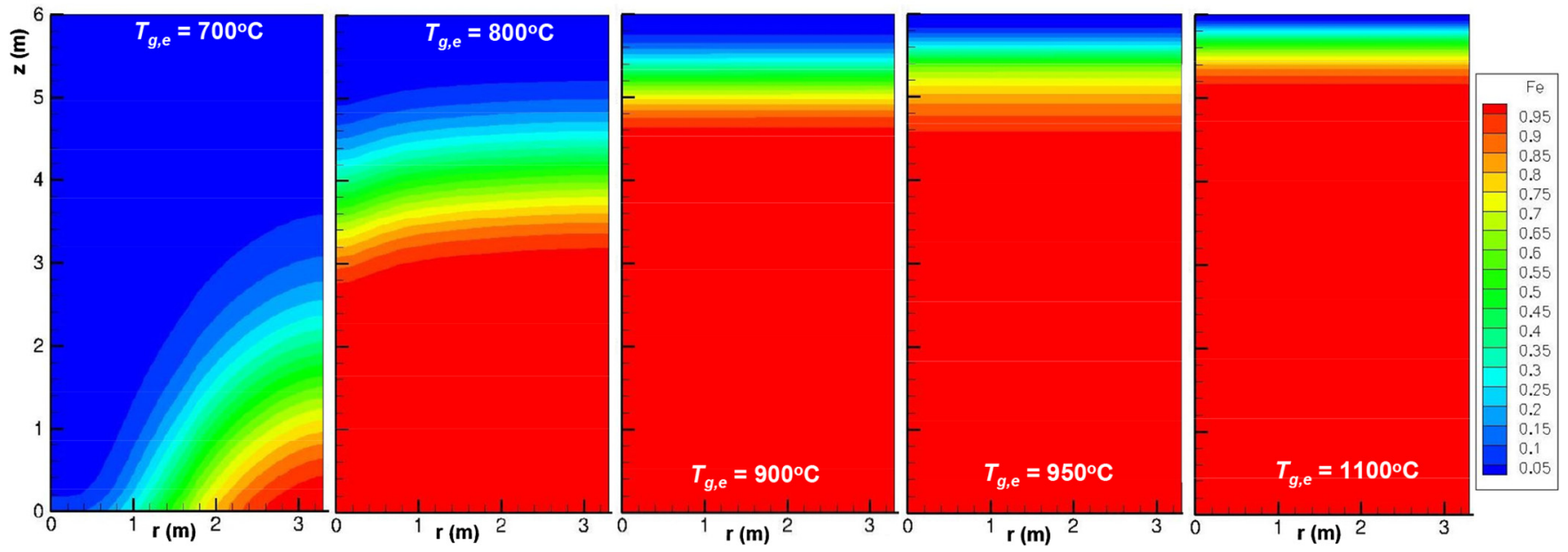

Fig. 14. Effect of the bustle gas temperature $\left(\mathrm{T}_{\mathrm{g}, \mathrm{e}}: 700\right.$ to $\left.1100^{\circ} \mathrm{C}\right)$ on the iron mass fraction in a shaft furnace fed with $\mathrm{H}_{2}$.

more industrial questions such as the integration of a direct reduction unit in a conventional integrated plant, with its consequences on the valorization of the coke oven, $\mathrm{BF}$ and BOF gases and on the best use of the DRI.

\section{References}

1. WorldSteel Association, Steel Statistical Yearbook 2020, 2020 https://www.worldsteel.org/steel-by-topic/statistics/ steel-statistical-yearbook.html (accessed on 25/10/2021)

2. L. Holappa, A general vision for reduction of energy consumption and $\mathrm{CO}_{2}$ emissions from the steel industry, Metals 10, $1117(2020)$

3. J.-P. Birat, M. Antoine, A. Dubs, et al., Vers une sidérurgie sans carbone?, in: Journées sidérurgiques 1992, 16 au 17 décembre, 1992 and Revue de métallurgie 90, 411 (1993)

4. CIRCORED Hydrogen-based reduction, METSO-OTTOTEC, https://www.mogroup.com/portfolio/circored-hydrogen-based-reduction

5. J.-P. Birat, J. Borlée, B. Korthas, et al., ULCOS program: A progress report in the spring of 2008, in: Scanmet III, 3rd International Conference on Process Development in Iron and Steelmaking, 8-11 June, 2008, Lulea, Sweden

6. J.-P. Birat, $\mathrm{CO}_{2}$-lean steelmaking: ULCOS, other international programs and emerging concepts, in: ECCR Steel (METEC- 2011), 2011

7. J.-P. Birat, The progress and status of IISI's $\mathrm{CO}_{2}$ Breakthrough Program and EU's ULCOS, in: $\mathrm{CO}_{2}$ Reduction Workshop, Kaohsiung, Taiwan, 1-2 November, 2007

8. Breaking through the technology barriers: Steel producers are researching new production technologies that would radically reduce their environmental footprint, FACT SHEET - Breakthrough technologies, Worldsteel pamphlet, $10 / 2008$

9. J.-P. Birat, F. Patisson, O. Mirgaux, Hydrogen Steelmaking, part 2: Competition with other zero-carbon steelmaking solutions-geopolitical issues, Matériaux \& Techniques, (2021), in press

10. M. Hutson, The promise of carbon-neutral steel, The New Yorker, Sept. 18, 2021, https://www.newyorker.com/news/ annals-of-a-warming-planet/the-promise-of-carbon-neutralsteel (accessed on 26 October 2020)
11. F. Patisson, O. Mirgaux, Hydrogen ironmaking: How it works, Metals 10, $922(2020)$

12. Hybrit (Hydrogen Breakthrough Ironmaking Technology) brochure, Available from https://ssabwebsitecdn.azureedge. net/-/media/hybrit/files/hybrit_brochure.pdf (accessed on $26 / 11 / 2020)$

13. A. Ranzani da Costa, D. Wagner, F. Patisson, Modelling a new, low $\mathrm{CO}_{2}$ emissions, hydrogen steelmaking process, J. Clean. Prod. 46, 27-35 (2013)

14. N. Towhidi, J. Szekely, Reduction kinetics of commercial low-silica hematite pellets with $\mathrm{CO}-\mathrm{H}_{2}$ mixtures over temperatures range $600-1234^{\circ} \mathrm{C}$, Ironmak Steelmak. 6, 237-249 (1981)

15. A. Bonalde, A. Henriquez, M. Manrique, Kinetic analysis of the iron oxide reduction using hydrogen-carbon monoxide mixtures as reducing agent, ISIJ Int. 45(9), 155-1260 (2005).

16. MIDREX, https://www.midrex.com/technology/midrexprocess / (accessed on 26/10/2020)

17. HYL-ENERGIRON, https://www.tenova.com/product/ iron-reduction-technologies/ (accessed on 26/10/2020)

18. H. Hamadeh, Modélisation mathématique détaillée du procédé de réduction directe du minerai de fer, Ph.D. Thesis, Université de Lorraine, Nancy, France, 2017, Available from https://tel.archives-ouvertes.fr/tel-01740462

19. A. Ranzani da Costa, La réduction du minerai de fer par l'hydrogène: étude cinétique, phénomène de collage et modélisation, Ph.D. Thesis, Institut national polytechnique de Lorraine, Nancy, France, 2011, Available from https://tel. archives-ouvertes.fr/tel-01204934/

20. H.Y. Sohn, The law of additive reaction times in fluid-solid reactions, Metall. Trans. 9B, 89-96 (1978)

21. H. Hamadeh, O. Mirgaux, F. Patisson, Detailed modeling of the direct reduction of iron ore in a shaft furnace, Materials 11, 1865 (2018)

22. D.R. Parisi, M.A. Laborde, Modeling of counter current moving bed gas-solid reactor used in direct reduction of iron ore, Chem. Eng. J. 104, 35-43 (2004)

23. M.S. Valipour, Y. Saboohi, Numerical investigation of nonisothermal reduction of haematite using syngas: The shaft scale study, Model. Simul. Mater. Sci. Eng. 15, 487-507 (2007)

24. A. Shams, F. Moazeni, Modeling and simulation of the MIDREX shaft furnace: reduction, transition and cooling zones, JOM 67, 2681-2689 (2015) 
25. K. Rechberger, et al., Green hydrogen-based direct reduction for low-carbon steelmaking, Steel Res. Int. 91, 2000110 (2020)
26. L. Shao et al., Computational analysis of hydrogen reduction of iron oxide pellets in a shaft furnace process, Renew. Energy 179, 1537-1547 (2021)

Cite this article as: Fabrice Patisson, Olivier Mirgaux, Jean-Pierre Birat, Hydrogen steelmaking. Part 1: Physical chemistry and process metallurgy, Matériaux \& Techniques 109, 303 (2021) 